\title{
Standard task set for evaluating rehabilitation interventions for individuals with arm paralysis
}

\author{
Andrew S. Cornwell, PhD; ${ }^{1}$ James Y. Liao; ${ }^{1}$ Anne M. Bryden, OTR; ${ }^{1}$ Robert F. Kirsch, PhD $^{1-2^{*}}$ \\ ${ }^{1}$ Department of Biomedical Engineering, Case Western Reserve University, Cleveland, $\mathrm{OH} ;{ }^{2}$ Louis Stokes Cleveland \\ Department of Veterans Affairs Medical Center, Functional Electrical Stimulation Center of Excellence, Cleveland, $\mathrm{OH}$
}

\begin{abstract}
We have developed a set of upper-limb functional tasks to guide the design and test the performance of rehabilitation technologies that restore arm motion in people with high tetraplegia. Our goal was to develop a short set of tasks that would be representative of a much larger set of activities of daily living (ADLs), while also being feasible for a user of a unilateral, implanted functional electrical stimulation (FES) system. To compile this list of tasks, we reviewed existing clinical outcome measures related to arm and hand function and were further informed by surveys of patient desires. We ultimately selected a set of five tasks that captured the most common components of movement seen in ADLs and is therefore highly relevant for assessing FES-restored unilateral arm function in individuals with high cervical spinal cord injury. The tasks are intended to be used when setting design specifications and for evaluating and standardizing rehabilitation technologies under development. While not unique, this set of tasks will provide a common basis for comparing different interventions (e.g., FES, powered orthoses, robotic assistants) and testing different user command interfaces (e.g., sip-and-puff, head joysticks, brain-computer interfaces).
\end{abstract}

Key words: activities of daily living, functional assessment, functional electrical stimulation, functional evaluation, functional neuromuscular stimulation, outcome measures, spinal cord injury, tasks, tetraplegia, upper limb.

\section{INTRODUCTION}

Functional electrical stimulation (FES) is a technology that allows individuals with paralysis to regain movement of their limbs by coordinated application of small amounts of electrical current to appropriate paralyzed muscles [1]. Currently, we are developing an FES system [2-3] to restore movement to individuals with high-level (cervical level 1-4) spinal cord injury (SCI), providing basic arm motions and, thus, increasing independence in simple yet critical activities of daily living (ADLs). The performance of the various components of this FES system (e.g., user command interfaces, feedback control systems) must be assessed under functionally relevant conditions and in a reasonably short period.

Our goal was therefore to compile a set of simple ADLs that is fairly brief but that (1) can be used to extrapolate performance under a much wider range of movements and (2) is feasible for a unilateral FES recipient. This same set of activities will be equally relevant for evaluating other rehabilitation interventions, such as robotic assistants and mobile arm supports. The purpose

Abbreviations: $\mathrm{ADL}=$ activity of daily living, $\mathrm{ADLAT}=\mathrm{ADL}$ Abilities Test, BI $=$ Barthel Index, FES = functional electrical stimulation, FIM = Functional Independence Measure, MBI = Modified BI, MTM = methods-time measurement, QIF = Quadriplegia Index of Function, RLAT $=$ Rancho Los Amigos Test, SCI = spinal cord injury, SCIM = Spinal Cord Independence Measure.

*Address all correspondence to Robert F. Kirsch, PhD; Case Western Reserve University, Department of Biomedical Engineering, Wickenden Bldg 10900, Euclid Ave, Cleveland, OH 44106; 216-368-3158; fax: 216-368-4969.

Email: rkf3@case.edu

http://dx.doi.org/10.1682/JRRD.2011.03.0040 
of these tasks is to aid in the development, preclinical evaluation, and, ultimately, clinical assessment of rehabilitation technologies that restore arm and hand functionality in people with high tetraplegia.

Many clinical measures have been developed to quantify the functional abilities of individuals with motor deficits, some based on ADLs and some on more specific motor control tasks that translate into increased function. These measures have been used in rehabilitation to document changes in a patient's status over time and to empirically evaluate the effectiveness of interventions. Several recent reviews have examined the literature related to these clinical measures [4-5]. Although many of these measures are theoretically applicable to individuals with high tetraplegia, almost none of the tasks required by these assessment tools will be possible for these individuals-even if they have a state-of-the-art FES system. Further, two surveys of a high-level SCI population have identified arm and hand function as being crucial to improved quality of life, although no specific tasks were mentioned [6-7].

To be more useful in providing a graded evaluation of interventions for high tetraplegia, a functional assessment tool will need to take into account the unique properties of this population and the nature of likely interventions (e.g., an FES system). These properties include the unilateral implementation of current FES systems, the complete paralysis of the lower limbs, paralysis of the torso that prevents whole-body movements typically synergistic with arm motions, the relative weakness of muscles under FES control, and the typical limitation of FES-restored hand function to lateral and palmar grasps only. In addition, common assessment tools do not accurately represent the realistic functional goals of FES users with high tetraplegia.

This study relied upon the published literature and the experience of the Cleveland FES Center to develop a list of five functional tasks that are representative of a larger set of important ADLs and that can be used to test novel upper-limb FES systems and other rehabilitation interventions. These tasks were also selected according to their ability to be programmed into a virtual reality environment that will be used in the future to test the performance and usability of novel user interfaces for upperlimb FES systems.

\section{METHODS}

Our general approach for compiling a reasonably small but representative set of hand and arm tasks for evaluating functional interventions for high tetraplegia was to (1) compile a comprehensive list of ADLs for the hand and arm from a variety of sources, (2) eliminate tasks that would not be feasible for an individual with a state-of-the-art intervention for high tetraplegia, (3) classify the feasible tasks into a common set of movement segments and count the various movement segment types in each given movement, and (4) select a small set of five simple tasks that encompasses all of the important movement components.

We consulted two different sources to draw conclusions about the relative importance of functional tasks for individuals with high tetraplegia: (1) the literature for studies on clinical measures and patient surveys and (2) consultations with rehabilitation professionals and FES users.

\section{Clinical Measures}

We drew from seven published clinical measures that address upper-limb function. The basis of this list comes from the excellent review by van Tuijl et al. [4], and includes the Barthel Index (BI), the Rancho Los Amigos Test (RLAT), the Functional Independence Measure (FIM), the Quadriplegia Index of Function (QIF), the Spinal Cord Independence Measure (SCIM), the ADL Abilities Test (ADLAT), and the Valutazione Funzionale Mielolesi (SCI Functional Assessment).

No one measure was perfectly applicable. Rather, the final list of tasks for this study was formed from an amalgam of activities and tasks identified across these clinical measures. The fact that a specific task was included in many existing assessment tools does not necessarily imply that this task was a high priority for our target population. However, we do assume that-for clinical measures especially-inclusion in several measures indicates a task that may contribute greatly to an overall increase in independence.

The oldest applicable measures in the literature are the BI [8] and its revision, the Modified BI (MBI) [9]. They were designed to assess independent self-care in individuals with tetraplegia. For the purposes of this study, the relevant tasks of the MBI are drinking from a cup, eating from a dish, and grooming. The RLAT Functional Activities subscale is another test developed to analyze the ability of individuals with high SCI to perform 
self-care activities. The test covers eight categories: feeding, grooming, toileting and bathing, upper-limb dressing, lower-limb dressing, written communication, desk skills, and transfers [10]. The FIM is the most cited measure in the rehabilitation literature [11-12]. Appropriate items for high tetraplegia in the FIM include eating and grooming, but no more specific, relevant tasks beyond these general measures are included. The QIF was developed specifically to document improvement in individuals with tetraplegia [13]. The feeding category of the QIF has been found to show more sensitivity than other measures, such as the FIM [14]. The SCIM, developed in 1997, was specifically designed to address the needs of individuals with SCI; it was revised in 2001 [15-16] and 2007 [17] and is now called the SCIM-III. Applicable tasks listed in this test are cutting food, opening containers, bringing food to mouth, drinking from a cup, washing hands, brushing teeth, combing hair, shaving, and applying makeup. The ADLAT was developed to analyze specific phases of tasks using a task analysis approach [18]. The six core tasks of the ADLAT are eating with a fork, drinking from a glass, writing with a pen, dialing a phone, using a compact disc, and brushing teeth.

In a somewhat different approach, the Valutazione Funzionale Mielolesi (SCI Functional Assessment) was designed as a way to identify changes in a specific patient's functional status over time, rather than as a measure to compare across patients for research purposes [19]. It includes 65 specific tasks, including the following, which were deemed appropriate for this study: uses fork, uses spoon, uses knife, pours [a pitcher] out, uses cup or glass, washes hands, washes face, dries hand/face, brushes teeth, shaves/puts on makeup, combs hair, writes in longhand, types, turns page, uses phone, uses remote control, opens/closes door, uses keys, and uses elevator.

A final set of often cited ADLs also informed our conclusions. The Klein-Bell ADL Scale is a large set of activities from six domains [20]. Not specific for SCI, the test has been shown to document small changes in independence with various ADLs. The many activities described in this measure were not specifically included in the analysis for this study because they are highly specific.

\section{Patient Surveys}

Surveys directed at patient populations who have limited arm and hand function further informed the selection of the functional task list. Knowledge of the stated desires of those without arm and hand function enabled a choice of tasks that will be functionally relevant and of high priority to potential FES users.

Donnelly et al. identified functional limitations in the SCI population associated with several broad areas [21]. The study surveyed 41 patients with SCI in the early stage of recovery for their perceived level of satisfaction and performance in these areas. The top five identified issues were functional mobility, including transfers and wheelchair use (19\%); dressing (13\%); grooming (11\%); feeding (8\%); and bathing (7\%). Kilgore et al. interviewed nine patients with SCI regarding priorities for research in FES and rehabilitation [22]. Each person was asked, "Can you prioritize the 2-3 activities that you would really like to be able to do that your injury prevents you from doing now?” Responses varied, but tended to include more specific activities such as walking, playing catch, dancing, changing an overhead light bulb, winding a clock, or cooking a meal. A common theme was frustration with the amount of time it took to complete ADLs. Another strong theme was the desire for independence and to not have to wait for caregivers or assistants. In 2004, Anderson performed a survey of 681 individuals with SCI to determine specific research activities that would most improve quality of life [6]. Nearly half of individuals with tetraplegia reported that regaining arm and hand function would most improve their quality of life, although no specific tasks were listed. In the same year, Snoek et al. published a similar survey of 565 subjects to determine the relative importance of hand function and seven other SCI impairment areas [7]. The study concluded that hand function improvement is a high priority compared with other impairments in tetraplegia, again without specific tasks cited.

Barreca et al. performed a literature search and survey to identify tasks for a new clinical measure for arm and hand activity in stroke patients [23]. This measure is called the Chedoke Arm and Hand Activity Inventory (or CAHAI) and is more relevant to the current study as a survey rather than a clinical measure. The following items were listed as priority at least three times: combing hair, dressing using buttons, raising glass to mouth, pouring water from glass, moving a can onto shelf and down again, preparing a hot drink, preparing a snack, cutting softer food, opening and closing a door, bringing a spoon to the mouth, writing, using/dialing the phone, reading books, picking up coins from a table, picking up a key and opening a lock, washing a floor, vacuuming, washing 
clothes by hand, opening and closing a jar, pulling on a shirt, and tying shoelaces.

To identify tasks for rehabilitation robots, Stanger et al. reviewed user task priorities generated by seven surveys conducted between 1966 and 1991 [24]. A sample of patients, representing SCI, multiple sclerosis, and other impairments, was interviewed. The top priorities of potential users were drinking from a glass, opening doors, washing/drying the face, using a vending machine, gardening, and manipulating printouts. Atkins et al. performed a comprehensive survey of children and adults with upper-limb loss [25]. The goal included identifying the "priorities identified by users as the most important areas for improvement in current prosthetic devices and future designs.” Users of many types of prostheses returned 1,575 surveys. Patients ranked the top activities they would like to be able to perform with their prostheses. The top activities, combined across prosthesis types, were type/use word processor, open door with knob, tie shoelaces, use spoon or fork, drink from glass, fasten a button, use a hammer and nail, and cut meat.

The patient surveys were used, qualitatively, to ensure that tasks of high importance to potential users were included in the final selection. For instance, the high emphasis on grooming and feeding ensured that several tasks contained movements around the face, which would be essential to complete any of these high-value ADLs. This helped ensure that the final selection of tasks for this study was not only representative of many other ADLs, but that each task was important in itself.

\section{Conversations with Rehabilitation Professionals and FES Users}

Our final selection of tasks was also influenced by the experience of rehabilitation professionals and our experience with FES systems in practice. We worked with one physician in physical medicine and rehabilitation, one occupational therapist, one physical therapist, and two current users of FES systems. The conversations were intentionally informal, unstructured discussions that allowed exploration of each participant's clinical and personal experience.

These discussions emphasized that many of the tasks deemed important by clinical measures and surveys are not feasible for individuals with severe impairments using existing or immediately foreseeable FES technology. These limitations include any task requiring bimanual manipulations; high levels of force; hand positions outside a nonimpaired, central reaching work space; or highly dexterous object manipulation. The results of these conversations are summarized largely by the "Feasibility Filter" illustrated in Figure 1, which indicates which tasks were eliminated from further analysis because of a consensus on their impracticality.

\section{RESULTS}

\section{Common Themes for Creation of Functional Task List}

As described in the "Methods," we created a set of representative tasks by starting with a large list of tasks identified in literature and then culling that list using the experience of those in the field. We then identified the

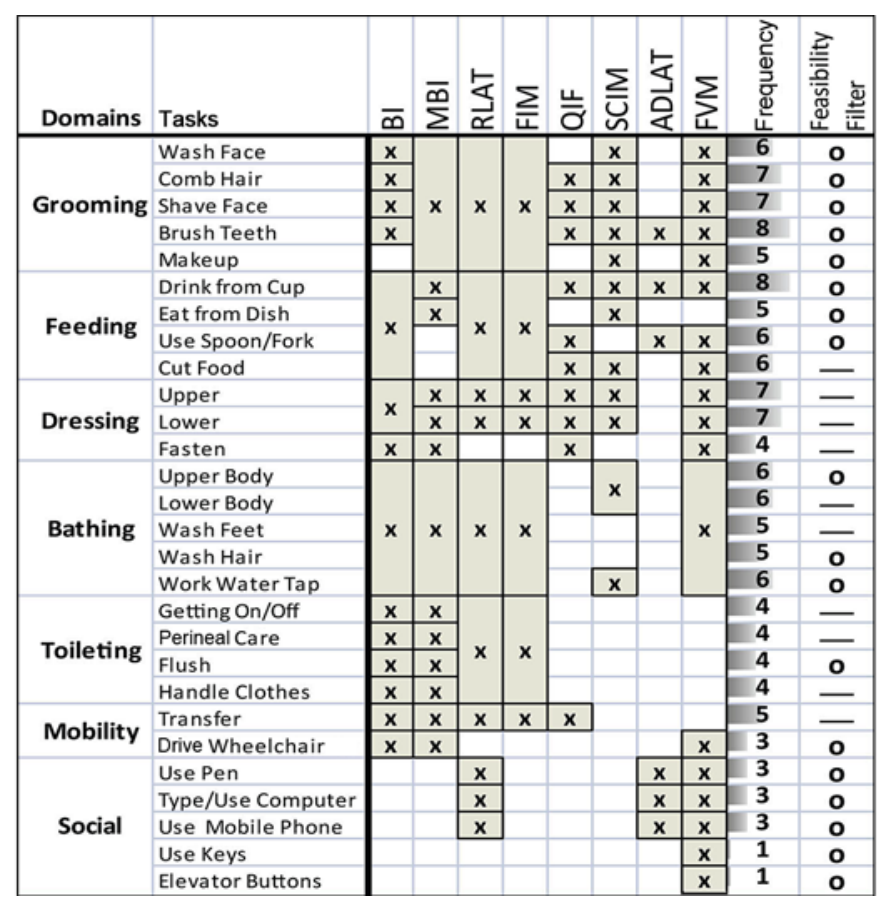

Figure 1.

Summary of clinical measures. Each clinical assessment measure evaluated is listed across top, with specific tasks mentioned in that assessment tool indicated along left side. Frequency is count of how many times specific task was used across all clinical measures. Feasibility filter marks tasks as possible ("o") or not possible ("-") with foreseeable high tetraplegia functional electrical stimulation system. ADLAT = Activity of Daily Living Abilities Test, $\mathrm{BI}=$ Barthel Index, FIM = Functional Independence Measure, FVM = Valutazione Funzionale Mielolesi, MBI = Modified BI, QIF = Quadriplegia Index of Function, RLAT = Rancho Los Amigos Test, SCIM = Spinal Cord Independence Measure. 
movement components used to complete each task and finally created a new small set of functional tasks that included the movement components most commonly required for the larger, complete set. After reviewing the literature, we were able to create an initial list of 28 tasks in 7 domains, as summarized in Figure 1. The tasks and their domains are indicated in the first two columns. The remaining columns, one for each of the relevant clinical measures, indicate (by an " $\boldsymbol{x}$ ") whether a given clinical measure included each of the 28 tasks. The "frequency" column indicates how many of the various clinical measures included a specific task. The rightmost column indicates (by an "o") whether each task would be a feasible goal for FES-restored movements in individuals with high tetraplegia (based on previous section). Overall, all tasks were represented in at least one clinical measure, and the feasibility filter reduced the initial task list to 18 .

\section{Movement Components}

Figure 2 lists the 18 feasible tasks selected from Figure 1 in the columns labeled at the top. The rows of Figure 2 (labeled "movement components") list the different movement components-from a start position (with the arm resting on the armrest) to the completion of the task - that comprised the movements of interest in this study. An " $x$ " across each of these rows indicates that a particular movement component was necessary for a particular functional activity. The rightmost column indicates how many times each of the movement components was included in the various feasible tasks.

Tasks were broken into components in a method similar to that used in the study of methods-time measurement (MTM), a method for predicting how long it should take a worker to complete a workplace task. This technique has been used in ADL analysis before [26]. However, unlike typical MTM, no restrictions are placed on the precise sequence of movements. In this case, a movement component was marked only if the task could not be completed without that component. If a task was possible without that movement component, then that component was not considered part of the task.

Note that the movement components are listed from top to bottom in order of their frequencies in the chosen functional tasks; i.e., "lift arm from armrest" occurred the most times (16) and is thus listed at the top. The frequencies of occurrence for the movement components are important, because the movement components in the final list of functional tasks should approximate the relative frequency of components in the actual ADLs.

\section{Functional Task List}

Based on the movement components presented in Figure 2, five composite tasks were chosen as representative activities that would be important and relevant to an individual with a high-level SCI and an FES neural prosthesis. The tasks were chosen empirically, with the twin goals of choosing tasks that are themselves important and those representing the movement components from Figure 2. Ideally, the representative tasks in the functional task list should represent all the movement components identified in the list of desired activities and replicate the relative frequency of the movement components. These selected tasks are-

1. Touching the face.

2. Drinking from a mug with a straw.

3. Eating with fingers from a plate.

4. Retrieving an object from a countertop.

5. Pressing an elevator button.

These tasks, along with their relationships to the 18 identified movement components, are indicated in Figure 3 . The columns in this figure indicate (with an " $x$ ") if a movement component is needed to complete the functional task. The rightmost column shows how often the movement component is used in all five functional tasks. Note that the relative frequency of motion segments in the functional task list is similar to the frequency of motion components identified by clinical tests, an important indicator of how completely the functional task list encompasses the entire list of desired functional activities.

\section{DISCUSSION}

We have developed a set of functional tasks to evaluate the performance of an FES neural prosthesis or any other intervention for restoring arm movements in high tetraplegia. The set of tasks is short, representative of a variety of movements, and feasible for a unilateral FES recipient. Our set of five tasks includes all of the movement components relevant to an individual with complete arm paralysis and an FES system and replicates the relative frequencies of these movement components seen in a much larger set of "feasible tasks." Thus, these five tasks represent a much broader range of movements, so performance in these five movements reflects likely performance in many relevant 


\begin{tabular}{|c|c|c|c|c|c|c|c|c|c|c|c|c|c|c|c|c|c|c|c|c|}
\hline & Feasible Tasks & 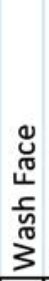 & 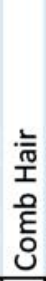 & 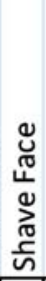 & 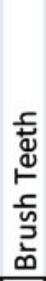 & $\begin{array}{l}\frac{0}{3} \\
\frac{d}{\pi} \\
\sum\end{array}$ & $\begin{array}{l}\frac{0}{3} \\
\text { E } \\
\text { 은 } \\
\text { 는 } \\
\text { 든 }\end{array}$ & 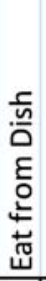 & 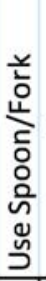 & 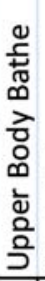 & $\begin{array}{l}\frac{1}{\pi} \\
\frac{1}{1} \\
\frac{1}{n} \\
\frac{\pi}{3} \\
3\end{array}$ & 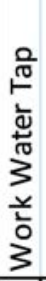 & $\frac{\sqrt{n}}{\frac{3}{4}}$ & 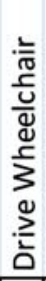 & 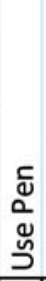 & 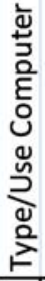 & 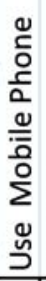 & & 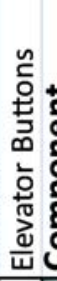 & 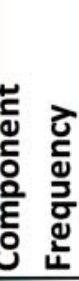 \\
\hline \multirow{17}{*}{ 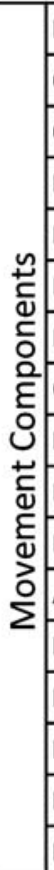 } & Lift arm from armrest & $\mathbf{x}$ & $\mathbf{x}$ & $\mathbf{x}$ & $\mathbf{x}$ & $\mathbf{x}$ & $\mathbf{x}$ & $\mathbf{x}$ & $\mathbf{x}$ & $\mathbf{x}$ & $\mathbf{x}$ & $\mathbf{x}$ & & & $\mathbf{x}$ & $\mathbf{x}$ & $\mathbf{x}$ & $\mathbf{x}$ & $\mathbf{x}$ & 16 \\
\hline & Orient hand for grasp & $\mathbf{x}$ & $x$ & $\mathbf{x}$ & $x$ & $\mathbf{x}$ & $\mathbf{x}$ & & & & $\mathbf{x}$ & $\mathbf{x}$ & & & & & & & & 8 \\
\hline & Obtain object from counter & $\mathbf{x}$ & $x$ & $\mathbf{x}$ & $x$ & $x$ & & & & $\mathbf{x}$ & $\mathbf{x}$ & & & & & & & & & 7 \\
\hline & Move hand: armrest to table height & & & & & & $\mathbf{x}$ & $\mathbf{x}$ & $\mathbf{x}$ & & & & & & $\mathbf{x}$ & $\mathbf{x}$ & $\mathbf{x}$ & $\mathbf{x}$ & & 7 \\
\hline & Move hand: armrest to counter height & $x$ & $x$ & $x$ & $x$ & $\mathbf{x}$ & & & & & $\mathbf{x}$ & & & & & & & & & 6 \\
\hline & Move hand: counter to head & $x$ & $\mathbf{x}$ & $\mathbf{x}$ & $\mathbf{x}$ & $\mathbf{x}$ & & & & & $\mathbf{x}$ & & & & & & & & & 6 \\
\hline & Maintain position: at face & $\mathbf{x}$ & & $\mathbf{x}$ & $\mathbf{x}$ & $\mathbf{x}$ & & & $\mathbf{x}$ & & & & & & & & & & & 5 \\
\hline & Obtain object from table & & & & & & $\mathbf{x}$ & $\mathbf{x}$ & $\mathbf{x}$ & & & & & & $\mathbf{x}$ & & & $\mathbf{x}$ & & 5 \\
\hline & \multicolumn{5}{|c|}{ Move hand: armrest to outside central workspace } & & & & & & & $\mathbf{x}$ & $\mathbf{x}$ & & & & & $\mathbf{x}$ & $\mathbf{x}$ & 4 \\
\hline & Move hand: table height to head & & & & & & $\mathbf{x}$ & $\mathbf{x}$ & $\mathbf{x}$ & & & & & & & & & & & 3 \\
\hline & Maintain orientation & & & & $x$ & & $\mathbf{x}$ & & $\mathbf{x}$ & & & & & & & & & & & 3 \\
\hline & Apply force through object & & & & & & & & $\mathbf{x}$ & & & & & & & & & $\mathbf{x}$ & & 2 \\
\hline & Precise positioning of object on table & & & & & & & & $\mathbf{x}$ & & & & & & $\mathbf{x}$ & & & & & 2 \\
\hline & Precise positioning of hand at table & & & & & & & & & & & & & & & $\mathbf{x}$ & $\mathbf{x}$ & & & 2 \\
\hline & Maintain position: over top of head & & $x$ & & & & & & & & & & & & & & & & & 1 \\
\hline & Move hand: counter to body & & & & & & & & & $\mathbf{x}$ & & & & & & & & & & 1 \\
\hline & \multicolumn{2}{|l|}{ Precise positioning of object at endpoint } & & & & & & & & & & & & & & & & $\mathbf{x}$ & & 1 \\
\hline
\end{tabular}

Figure 2.

Breaking tasks into movement components: 18 feasible tasks from Figure 1 are listed across top of chart. Along left side are components of movement that make up feasible tasks, from start of movement to completion. "Component Frequency" is total number of times each component is performed in order to complete all feasible tasks.

tasks. This should allow these tasks to be used as a functional benchmark for developing and deploying rehabilitation technologies.

While we believe that this list is most representative for the high tetraplegia population, it could easily be changed according to the movement impairment of a given patient population and/or the desires of a specific user. The framework identified here serves as a template for creating a new list meeting the desired criteria, for example by modifying the "feasibility filter."

No relevant standard exists for evaluating movement restoration for individuals with high tetraplegia, since until recently no movement-related rehabilitation has been available. With the development of FES systems for high tetraplegia, the need for a functionally relevant method of evaluating the outcome of intervention has grown. For our purposes, the main limitation of existing surveys and clinical measures is that they focus on a loss of function specific to one condition. Since the options for high tetraplegia rehabilitation are very limited, no functional measures exist designed specifically to assess the motor performance of someone with paralysis to this extent. Understanding this, we examined the literature in a more general, thematic way to produce a simple list of tasks whose execution could represent the future functional ability of an arm enabled with FES. These tasks could be used to evaluate different types of FES systems, command interfaces (e.g., brain-computer interface, electromyography, tongue pad, voice), control algorithms 


\begin{tabular}{|c|c|c|c|c|c|c|c|}
\hline & & \multicolumn{5}{|c|}{ Functional Task List } & \multirow[b]{2}{*}{ 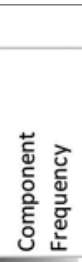 } \\
\hline & & 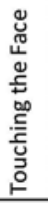 & 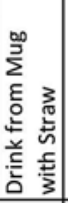 & 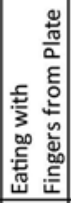 & 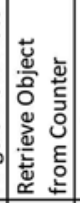 & 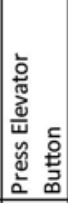 & \\
\hline \multirow{17}{*}{ 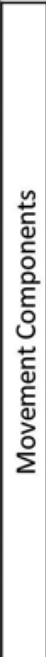 } & Lift arm from armrest & $\mathrm{x}$ & $\mathrm{x}$ & $\mathrm{x}$ & $\mathrm{x}$ & $\mathrm{x}$ & 5 \\
\hline & Orient hand for grasp & & $\mathbf{x}$ & $\mathrm{x}$ & $\mathrm{x}$ & & 3 \\
\hline & Obtain object from counter & & & & $\mathbf{x}$ & & 1 \\
\hline & Move hand: armrest to table height & & $\mathrm{x}$ & $\mathrm{x}$ & & & 2 \\
\hline & Move hand: armrest to counter height & & & & $\mathrm{x}$ & & 1 \\
\hline & Move hand: counter to head & $\mathrm{x}$ & & & & & 1 \\
\hline & Maintain position: at face & $\mathrm{x}$ & $\mathrm{x}$ & $\mathrm{x}$ & & & 3 \\
\hline & Obtain object from table & & $\mathrm{x}$ & $x$ & & & 2 \\
\hline & \multicolumn{3}{|c|}{ Move hand: armrest to outside central workspace } & & & $x$ & 1 \\
\hline & Move hand: table height to head & $\mathrm{x}$ & $\mathrm{x}$ & $x$ & & & 3 \\
\hline & Maintain orientation & & $x$ & & & & 1 \\
\hline & \begin{tabular}{|l|} 
Apply force through object \\
\end{tabular} & & & & & $\mathrm{x}$ & 1 \\
\hline & Precise positioning of object on table & & $x$ & & & & 1 \\
\hline & Precise positioning of hand at table & & $\mathrm{x}$ & $x$ & & & 2 \\
\hline & Maintain position: over top of head & & & & & & 0 \\
\hline & Move hand: counter to body & & & & $\mathbf{x}$ & & 1 \\
\hline & \begin{tabular}{|l|} 
Precise positioning of object at endpoint \\
\end{tabular} & & & & & $\mathrm{x}$ & 1 \\
\hline
\end{tabular}

Figure 3.

Functional task list. All movement components are listed in rows, and tasks of functional task list are listed across top. Frequency of each movement component is totaled in rightmost column. Note that frequency of each component in functional task list roughly resembles frequency of components in tasks from clinical measures.

(e.g., with or without feedback), or sensor integrations (i.e., comparison of sensor characteristics).

In addition, this set of tasks can provide a common basis for comparison of other interventions for high tetraplegia, including robots, powered exoskeletons, or different rehabilitation applications such as prosthetics for shoulder disarticulation amputees. We feel the utility of this method and these tasks is certainly not limited to FES applications in SCI. Finally, we anticipate that the tasks could be programmed into a virtual reality game environment to allow testing of any command and control scheme for the interventions or applications listed previously.

\section{CONCLUSIONS}

We have created a set of functional tasks that will provide a common basis for evaluating interventions such as FES for restoring arm movements in individuals with high tetraplegia and other severe paralytic disorders. The five tasks chosen (touching the face, eating with fingers from a plate, drinking from a mug with a straw, retrieving an object from a countertop, and pressing an elevator button) represent consistent themes in clinical measures and stated user desires, are important activities, and represent a larger set of similarly important motions. Through inclusion of tasks that are important in their own right, but also contain movement components common across a broader range of motions, the simple set of five tasks form a basis for setting design specifications and evaluating the technical performance and efficacy of various upper-limb rehabilitation interventions in SCI and other upper-limb movement disorders.

\section{ACKNOWLEDGMENTS}

\section{Author Contributions:}

Study concept and design: A. S. Cornwell.

Literature review: J. Y. Liao, A. S. Cornwell.

Analysis and interpretation of data: A. S. Cornwell, J. Y. Liao,

A. M. Bryden.

Drafting of manuscript: A. S. Cornwell, R. F. Kirsch.

Critical revision of manuscript for important intellectual content:

A. M. Bryden, R. F. Kirsch.

Obtained funding: R. F. Kirsch.

Study supervision: R. F. Kirsch.

Financial Disclosures: The authors have declared that no competing interests exist.

Funding Sources: This material was based on work supported by the National Institutes of Health, National Institute of Child Health and Human Development (grants N01-HD-5-340 and NIH T32:

T32EB004314).

\section{REFERENCES}

1. Peckham PH, Marsolais EB, Mortimer JT. Restoration of key grip and release in the C6 tetraplegic patient through functional electrical stimulation. J Hand Surg Am. 1980; 5(5):462-69. [PMID:6968764]

2. Blana D, Kirsch RF, Chadwick EK. Combined feedforward and feedback control of a redundant, nonlinear, dynamic musculoskeletal system. Med Biol Eng Comput. 2009; 47(5):533-42. [PMID:19343388] http://dx.doi.org/10.1007/s11517-009-0479-3

3. Polasek KH, Hoyen HA, Keith MW, Kirsch RF, Tyler DJ. Stimulation stability and selectivity of chronically implanted multicontact nerve cuff electrodes in the human 
upper extremity. IEEE Trans Neural Sys Rehabil Eng. 2009; 17(5):428-37.

4. Van Tuijl JH, Janssen-Potten YJ, Seelen HA. Evaluation of upper extremity motor function tests in tetraplegics. Spinal Cord. 2002;40(2):51-64. [PMID:11930877]

http://dx.doi.org/10.1038/sj.sc.3101261

5. Miller WC, Sakakibara BM, Noonan VK, Tawashy AE, Aubut JL, Connolly SJ, Curt A, Elliott S, Hsieh JT, Mortenson WB, Noreau L, Orenczuk SG, Sawatzky B, Steeves J, Wilkinson S, Wolfe DL. Outcome measures. In: Eng JJ, Teasall RW, Miller WC, Wolfe DL, Townson AF, Hsieh JT, Connolly SJ, Mehta S, Sakakibara BM, editors. Spinal cord injury rehabilitation evidence. Version 3.0. Vancouver (Canada): SCIRE; 2010. p. 1-147.

6. Anderson KD. Targeting recovery: Priorities of the spinal cordinjured population. J Neurotrauma. 2004;21(10):1371-83.

[PMID:15672628]

http://dx.doi.org/10.1089/neu.2004.21.1371

7. Snoek GJ, IJzerman MJ, Hermens HJ, Maxwell D, BieringSorensen F. Survey of the needs of patients with spinal cord injury: Impact and priority for improvement in hand function in tetraplegics. Spinal Cord. 2004;42(9):526-32. [PMID:15224087] http://dx.doi.org/10.1038/sj.sc.3101638

8. Mahoney FI, Barthel DW. Functional evaluation: The Barthel Index. Md State Med J. 1965;14:61-65.

[PMID:14258950]

9. Yarkony GM, Roth EJ, Heinemann AW, Lovell L, Wu YC. Functional skills after spinal cord injury rehabilitation: Three-year longitudinal follow-up. Arch Phys Med Rehabil. 1988;69(2):111-14. [PMID:3341888]

10. Rogers JC, Figone JJ. Traumatic quadriplegia: Follow-up study of self-care skills. Arch Phys Med Rehabil. 1980; 61(7):316-21. [PMID:7396683]

11. Keith RA, Granger CV, Hamilton BB. The FIM: A new tool for rehabilitation. Advances in clinical rehabilitation. New York: Springer Publishing; 1987. p. 10-18.

12. Hamilton BB, Laughlin JA, Fiedler RC, Granger CV. Interrater reliability of the 7-level Functional Independence Measure (FIM). Scand J Rehabil Med. 1994;26(3):115-19. [PMID:7801060]

13. Gresham GE, Labi ML, Dittmar SS, Hicks JT, Joyce SZ, Stehlik MA. The Quadriplegia Index of Function (QIF): Sensitivity and reliability demonstrated in a study of thirty quadriplegic patients. Paraplegia. 1986;24(1):38-44.

[PMID:3960588] http://dx.doi.org/10.1038/sc.1986.7

14. Marino RJ, Huang M, Knight P, Herbison GJ, Ditunno JF Jr, Segal M. Assessing selfcare status in quadriplegia: Comparison of the Quadriplegia Index of Function (QIF) and the Functional Independence Measure (FIM). Paraple- gia. 1993;31(4):225-33. [PMID:8493037]

http://dx.doi.org/10.1038/sc.1993.41

15. Catz A, Itzkovich M, Agranov E, Ring H, Tamir A. SCIM-Spinal Cord Independence Measure: A new disability scale for patients with spinal cord lesions. Spinal Cord. 1997;35(12):850-56. [PMID:9429264]

http://dx.doi.org/10.1038/sj.sc.3100504

16. Catz A, Itzkovich M, Agranov E, Ring H, Tamir A. The Spinal Cord Independence Measure (SCIM): Sensitivity to functional changes in subgroups of spinal cord lesion patients. Spinal Cord. 2001;39(2):97-100.

[PMID:11402366]

http://dx.doi.org/10.1038/sj.sc.3101118

17. Itzkovich M, Gelernter I, Biering-Sorensen F, Weeks C, Laramee MT, Craven BC, Tonack M, Hitzig SL, Glaser E, Zeilig G, Aito S, Scivoletto G, Mecci M, Chadwick RJ, El Masry WS, Osman A, Glass CA, Silva P, Soni BM, Gardner BP, Savic G, Bergström EM, Bluvshtein V, Ronen J, Catz A. The Spinal Cord Independence Measure (SCIM) version III: Reliability and validity in a multi-center international study. Disabil Rehabil. 2007;29(24):1926-33.

[PMID:17852230]

http://dx.doi.org/10.1080/09638280601046302

18. Bryden AM, Kilgore KL, Keith MW, Peckham HP. Assessing activity of daily living performance after implantation of an upper extremity neuroprosthesis. Top Spinal Cord Inj Rehabil. 2008;13(4):37-53.

http://dx.doi.org/10.1310/sci1304-37.

19. Taricco M, Apolone G, Colombo C, Filardo G, Telaro E, Liberati A. Functional status in patients with spinal cord injury: A new standardized measurement scale. Gruppo Interdisciplinare Valutazione Interventi Riabilitativi. Arch Phys Med Rehabil. 2000;81(9):1173-80.

[PMID:10987158] http://dx.doi.org/10.1053/apmr.2000.7161

20. Klein RM. The Klein-Bell ADL scale manual. Seattle (WA): University of Washington Medical School; 1979.

21. Donnelly C, Eng JJ, Hall J, Alford L, Giachino R, Norton $\mathrm{K}$, Kerr DS. Client-centred assessment and the identification of meaningful treatment goals for individuals with a spinal cord injury. Spinal Cord. 2004;42(5):302-7. [PMID:14993893] http://dx.doi.org/10.1038/sj.sc.3101589

22. Kilgore KL, Scherer M, Bobblitt R, Dettloff J, Dombrowski DM, Godbold N, Jatich JW, Morris R, Penko JS, Schremp ES, Cash LA. Neuroprosthesis consumers' forum: Consumer priorities for research directions. J Rehabil Res Dev. 2001;38(6):655-60. [PMID:11767973]

23. Barreca S, Gowland CK, Stratford P, Huijbregts M, Griffiths J, Torresin W, Dunkley M, Miller P, Masters L. Development of the Chedoke Arm and Hand Activity Inventory: Theoretical constructs, item generation, and 
selection. Top Stroke Rehabil. 2004;11(4):31-42. [PMID:15592988]

http://dx.doi.org/10.1310/JU8P-UVK6-68VW-CF3W

24. Stanger CA, Anglin C, Harwin WS, Romilly DP. Devices for assisting manipulation: A summary of user task priorities. IEEE Trans Rehabil Eng. 2002;2(4):256-65.

25. Atkins DJ, Heard DC, Donovan WH. Epidemiologic overview of individuals with upper-limb loss and their reported research priorities. J Prosth Orthot. 1996;8(1):2. http://dx.doi.org/10.1097/00008526-199600810-00003.

26. Burelbach JC, Crago PE. Instrumented assessment of FNS hand control during specific manipulation tasks. IEEE Trans Rehabil Eng. 2002;2(3):165-76.

Submitted for publication March 14, 2011. Accepted in revised form June 17, 2011.
This article and any supplementary material should be cited as follows:

Cornwell AS, Liao JY, Bryden AM, Kirsch RF. Standard task set for evaluating rehabilitation interventions for individuals with arm paralysis. J Rehabil Res Dev. 2012; 49(3):395-404.

http://dx.doi.org/10.1682/JRRD.2011.03.0040

ResearcherID: Andrew S. Cornwell, PhD: B-6156-2012

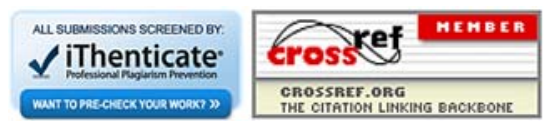


